\title{
Evolutionary Computation for Macroeconomic Forecasting
}

\author{
Oscar Claveria ${ }^{*}$, Enric Monte ${ }^{2}$, Salvador Torra ${ }^{3}$ \\ ${ }^{1}$ AQR-IREA, University of Barcelona (UB) \\ ${ }^{2}$ Department of Signal Theory and Communications, Polytechnic University of Catalunya (UPC) \\ ${ }^{3}$ Riskcenter-IREA, Department of Econometrics and Statistics, University of Barcelona (UB)
}

\begin{abstract}
The main objective of this study is twofold. First, we propose an empirical modelling approach based on genetic programming to forecast economic growth by means of survey data on expectations. We use evolutionary algorithms to estimate a symbolic regression that links survey-based expectations to a quantitative variable used as a yardstick, deriving mathematical functional forms that approximate the target variable. The set of empirically-generated proxies of economic growth are used as building blocks to forecast the evolution of GDP. Second, we use these estimates of GDP to assess the impact of the 2008 financial crisis on the accuracy of agents' expectations about the evolution of the economic activity in four Scandinavian economies. While we find an improvement in the capacity of agents' to anticipate economic growth after the crisis, predictive accuracy worsens in relation to the period prior to the crisis. The most accurate GDP forecasts are obtained for Sweden.
\end{abstract}

Keywords: Evolutionary algorithms; Symbolic regression; Genetic programming; Business and consumer surveys; Expectations; Forecasting

JEL Classification: C51; C55; C63; C83; C93

\section{Acknowledgements}

We would like to thank Johanna Garnitz at the Ifo Institut für Wirtschaftsforschung München for providing us the data used in the study. This research was supported by by the projects ECO201675805-R and TEC2015-69266-P from the Spanish Ministry of Economy and Competitiveness.

\footnotetext{
* Corresponding author. Tel.: +34-934021825; Fax.: +34-934021821. Department of Econometrics, University of Barcelona, Diagonal 690, 08034 Barcelona, Spain. E-mail address: oclaveria@ub.edu
} 


\section{Introduction}

Evolutionary computation is being increasingly applied in economics. The main idea behind evolutionary computation is the implementation of algorithms that adopt principles of the theory of natural selection to problem solving (Fogel 2006). These algorithms are known as evolutionary algorithms (EAs). One of the most implemented EAs in optimization problems is the genetic algorithm (GA) developed by Holland (1975). Cramer (1985) proposed a generalization of GAs known as genetic programming (GP), in which the solutions are expressed in the form of computer programs. Whereas GAs codes potential solutions by means of fixed length binary string representations, GP uses tree-structured, variable length representations suitable for non-linear modelling. This more general representation scheme allows the model structure to vary during the evolution. As a result, GP is particularly indicated for empirical modelling.

Empirical modelling consists on developing mathematical models from experimental data, which implies finding both the structure and the parameters of the model simultaneously. Koza (1992) developed a novel approach to empirical modelling based on symbolic regression (SR) via GP. SR can be regarded as a modelling technique used to construct regression models (such as linear regression, radial basis functions, support vector machines, kriging, etc.) by searching the space of mathematical expressions that best fit a given dataset. In this search there is usually a trade-off between accuracy and simplicity. Koza (1992) used GP to find the best single computer program that solves a given SR problem. This approach is especially useful to find patterns in large data sets, where little or no information is known about the system.

In this study we implement SR via GP to find the relationship between a wide range of expectational variables and economic growth. We use survey data on expectations from the World Economic Survey (WES) carried out by the CESIfo Institute for Economic Research. By combining a SR approach with GP, we derive mathematical functional forms that can be regarded as the optimal combinations of survey variables that best fit the actual evolution of the economic activity. We use these computationally-generated expressions as building blocks to forecast year-on-year growth rates of GDP.

Expectations about the state of the economy are key in economic modelling. One of the most common ways for agents to reveal their expectations is through tendency surveys. Business and consumer tendency surveys ask agents whether they expect a 
variable to rise, to remain constant, or to fall. The relationship between quantitative data and respondents' expectations was first formalised by Anderson (1952) and Theil (1952), who regressed the actual average percentage change of an aggregate variable on the percentage of respondents expecting a variable to rise and to fall. The theoretical framework for quantifying these percentages was initially based on the existence of an interval around zero within which respondents perceive there are no significant changes in the variable. Thus, respondents would answer that they expect a certain variable to go up (or down) to the extent that the mean of their subjective probability distribution lied beyond a threshold level. These thresholds could therefore be regarded as the limits of an indifference or imperceptibility interval. Carlson and Parkin (1975) developed this approach by using a normal distribution, and by assuming unbiasedness over the sample period to estimate the difference limen. This approach was latter extended by Pesaran $(1984,1985)$, who allowed the model for an asymmetrical relationship between the actual average percentage change and the agents' changes in periods of growth.

By matching individual responses with realisations, several authors have further explored this relationship at the micro level (Białowolski 2016; Breitung and Schmeling 2013; Lahiri and Zhao 2015; Lui et al. 2011a, 2011b; Mitchell et al. 2002, 2005a, 2005b; Mokinski et al. 2015; Müller 2010; Zimmermann 1997). Müller (2010) proposed a variant of the Carlson-Parkin method with asymmetric and time invariant thresholds. Breitung and Schmeling (2013) found that the introduction of asymmetric and time-varying thresholds was key in order to improve the forecast accuracy of quantified survey expectations, while the individual heterogeneity across forecasters seemed to play only a minor role. Using household-level data from the University of Michigan, Lahiri and Zhao (2015) found strong evidence against the threshold constancy, symmetry, homogeneity, and overall unbiasedness assumptions of the Carlos-Parkin method.

Experimental expectations generated by Monte Carlo simulations have also been used to delve into the relationship between individual expectations and their quantitative equivalent. Common (1985) generated simulated expectations to test the rational expectations hypothesis. Simulation experiments have also been used to assess the forecasting performance of different quantification methods of survey expectations. By means of individual computer-generated expectations, Claveria (2010) compared the forecasting performance of the main quantification methods, while Löffler (1999) and Terai (2009) estimated the measurement error introduced by the Carlson-Parkin method. 
The link between survey expectations and quantitative data at the aggregate level has been widely investigated (Abberger 2007; Batchelor and Dua 1998, 1992; Bergström 1995; Berk 1999; Bovi 2013; Bruestle and Crain 2015, Bruno 2014; Claveria et al. 2007; Dees and Brinca 2013; Driver and Urga 2004; Graff 2010; Hansson et al. 2005; JeanBaptiste 2012; Kauppi et al. 1996; Leduc and Sill 2013; Lee 1994; Mittnik and Zadrozny 2005; Nardo 2003; Nolte and Pohlmeier 2007; Pesaran and Weale 2006; Qiao et al. 2009, Rahiala and Teräsvirta 1993; Robinzonov et al. 2012; Smith and McAleer 1995; Sorić et al. 2013; Wilms et al. 2016). Klein and Özmucur (2010) analysed the role of survey expectations in 26 European countries, and found that they improved the forecasting performance of autoregressive time series models.

Schmeling and Schrimpf (2011) found that survey-based measures of expected inflation were significant predictors of future aggregate stock returns in France, Germany, Italy, the UK, the US and Japan, both in-sample and out-of-sample. Using survey expectations of 12 European countries, Ghonghadze and Lux (2012) obtained a superior out-of-sample forecasting performance with a canonical opinion dynamics model than with univariate time series models. Jonsson and Österholm (2012) analysed the inflation expectations formation process in Sweden using survey expectations, obtaining a poor forecasting performance that could be partly attributable to a mismeasurement of expectations. However, Österholm (2014) found that survey-based expectations improved the out-of-sample forecasting performance of GDP growth predictions in Sweden.

Martinsen et al. (2014) constructed factor models based on disaggregate survey data to forecast inflation, unemployment and GDP in Norway. The authors obtained the most accurate results for GDP growth. Girardi (2014) found that survey expectations contained relevant information about business cycle developments in the Euro Area (EA), especially around periods of extreme cyclical swings. Guizzardi and Stacchini (2015) showed that the inclusion of business survey indicators in time series models increased the forecasting accuracy of the baseline models. In a recent study, Altug and Çakmakli (2016) generated inflation forecasts by combining data on survey expectations with the inflation target set by central banks, finding the former to increase the predictive power of the models. Similarly, Lehmann and Wohlrabe (2017) found that consumers' unemployment expectations were a good indicator of employment growth in Germany. 
These studies use a wide range of econometric techniques, but none of them assesses the relationship between both official quantitative data and qualitative survey expectations by means of evolutionary methods. This research aims to break new ground by linking survey data and economic growth by means of evolutionary computation. We design a SR experiment in order to find the optimal combinations of survey expectations that best fit the actual evolution of year-on-year growth rates of GDP. Lahiri and Zhao (2015) found a significant improvement in agents' expectations accuracy during periods of uncertainty. This finding has also led us to assess the impact of the 2008 financial crisis on agents' ability to forecast the evolution of economic activity. Hence, we use the estimates of GDP in four Scandinavian economies and compare them to a baseline model by means of the mean absolute scaled error (MASE) proposed by Hyndman and Koehler (2006).

The rest of the paper is organized as follows. Sect. 2 presents our proposed methodological approach and the experimental set up. In Sect. 3 we present the empirical results. Finally, Sect. 4 provides some concluding remarks.

\section{Methodology}

GP is a soft computing search technique for problem-solving. GP's tree-structured programs are evolved by means of genetic operators for model approximation. In this study we design a SR experiment in order to derive a set of functional forms that link survey expectations to economic growth. This data-driven regression approach assumes no a priori model. Using EAs that apply Darwinian principles that imitate aspects of biological evolution, such as the principle of survival and reproduction of the fittest, an initial population of computer programs are bred through generations to find a set of analytical functions that best fit the data.

Koza (1992) developed GP for implementing SR. In his seminal paper, Koza (1995) applied GP to assess the non-linear "exchange equation", finding the empirical relationships between the price level, and gross national product, money supply, and the velocity of money. The versatility of this empirical modelling approach has attracted researchers from different areas (Álvarez-Díaz et al. 2009; Barmpalexis et al. 2011; Cai et al. 2006; Can and Heavey 2011; Ceperic et al. 2014; Sarradj and Geyer 2014; Wu et al. 2008; Yao and Lin 2009). 
Nevertheless, most of the applications of evolutionary computing to economics have been in finance (Goldberg 1989). Regarding GP, Álvarez-Díaz and Álvarez (2005) used GP to forecast exchange rates of the yen and the pound to the US dollar. Larkin and Ryan (2008) applied GP to nowcast stock prices using ordinal news sentiment data generated in real time by classifying financial news into positive, negative and neutral. The authors found that GP effectively predicted large intraday price jumps on the Standard \& Poor 500 return index (S\&P 500) up to an hour before they occurred without using current market prices information. Based upon its performance in eight stock markets and eight foreign exchange markets during three consecutive test periods, Chen et al. (2008) thoroughly analysed the application of GP to financial trading, shedding some light on how GP performance could be connected to the trending and cyclical properties of financial data. Wilson and Banzhaf (2009) compared a developmental co-evolutionary GP approach to standard linear GP for interday stock prices prediction. Vasilakis et al. (2013) presented a GP-based technique to predict returns in the trading of the euro/dollar exchange rate based on historical data and assessed its forecasting performance relative to four different approaches, obtaining the highest trading performance with the proposed method.

Regarding GAs, Acosta-González et al. (2012) used a GA to select the best econometric model for explaining the 2008 financial crisis, and found that the main determinant was the percentage of bank claims on private sector over deposits in the year 2006. By means of a computational search methodology based on GAs, Acosta-González and Fernández-Rodríguez (2014) selected the optimal financial ratios employed in a logit model to forecast bankruptcy in the Spanish building industry using annual public accounting information. Huang et al. (2015) presented a novel methodology for pairs trading using GAs. Sheta et al. (2015) modelled the S\&P 500 using multi-gene SR. Multigene SR is a special variation of the classic GP algorithms where each symbolic model is represented by a number of GP trees weighted by a linear combination. The method was used to evolve linear combinations of non-linear functions of 27 input variables, obtaining robust results when tracking the S\&P 500 index in a weekly basis. Ramos-Herrera and Acosta-González (2017) evaluated the factors explaining exchange rate stability in 17 economies of the European Union (EU) making use of GAs. Among the higher impact factors, the authors found that variables measuring competiveness, including agents' expectations, clearly stood out due to their repeated presence in the different models. For a review of the applications of GAs for financial forecasting see Drake and Marks (2002). 
Applications of evolutionary computation in economics are more recent. See Chen and Kuo (2002) for a classification of the literature on the application of evolutionary computation to economics and finance. Chen et al. (2010) introduced GP in a vector error correction model for macroeconomic forecasting. By means of SR via Pareto GP, Kotanchek et al. (2010) provided some insight into GDP forecasting. Duda and Szydło (2011) applied an improved version of GP known as gene expression programming (GEP) (Ferreria 2011) to develop a set of economic forecasting models. Kronberger et al. (2011) used SR to identify variable interactions between 33 economic indicators in order to estimate the evolution of prices in the US. Kl'účik (2012) used SR via GP in the estimation of total exports and imports to Slovakia. Krömer et al. (2013) presented an an application of GP to the evolution of fuzzy rules based on the concept of extended Boolean queries. In their approach, fuzzy rules are used as symbolic classifiers learned from data and used to label data records and to predict the value of an output variable. The authors used GP to find fuzzy rules labelling faulty products in a steel processing plant. Yang et al. (2015) used a data-driven approach based on SR to predict oil production in the US, using data from the 48 lower states since 1859 .

By means of GAs, Acosta-González et al. (2014) selected the best econometric model for explaining the determinants of the size of the shadow economy using data from 38 economies. The authors found that the main determinants of the shadow economy were: taxes on capital gains of individuals, corporate taxes on income, profits and capital gains, domestic credit, bank secrecy, ethnic fractionalization, urban population, globalization, corruption and the socialist legal origin of country. Kapetanios et al. (2016) assessed the forecasting performance of GAs and two other heuristic optimisation algorithms (simulated annealing and the $M C^{3}$ algorithm) to forecast quarterly GDP growth and monthly inflation in the EA based on a large set of 195 monthly indicators. The authors found that variable selection based on heuristic optimisation of information criteria often outperformed variable reduction methods (principal components, partial least squares, and Bayesian shrinkage regression). See Milutinović et al. $(2015,2017)$ and Petković (2015) for alternative heuristic optimisation strategies.

In a recent study, Marković et al. (2017) made use of ten science and technology factors as inputs for GDP growth prediction in $28 \mathrm{EU}$ countries. The authors compared the predictive accuracy of GP and other soft computing methods to that of extreme learning machines (ELMs) (Huang et al. 2006), and obtained the highest accuracy with 
ELMs were initially proposed as learning algorithms for single-hidden layer feedforward neural networks characterised by fast training time.

Among recent developments in evolutionary computation, Zelinka (2005) introduced analytical programming, and showed its ability to synthesize suitable solutions (programs) in SR. Maschek (2010) developed a two-level learning (or self-adaptation) mechanism and evaluated how it affected an economic application of GAs. Vladislavleva et al. (2010) evaluated different ways of improving SR by incorporating weights into the fitness function. Waltman et al. (2011) examined to what extent the use of binary encoding strategies influence the results produced by GAs. Peng et al. (2014) proposed an improved GEP algorithm especially suitable for dealing with SR problems. Gandomi and Roke (2015) compared the forecasting performance of ANN models to that of GEP techniques. See Dabhi and Chaudhary (2015) and Poli et al. (2010) for a review of the main issues related to GP.

GP allows to find patterns in large data sets. This feature is particularly suitable where little or no information is known about the system. As opposed to evolutionary programming (Fogel 1966), in which the structure of the program to be evolved remains fixed, GP simultaneously evolves the structure and the parameters of the models. We use GP to formalize the interactions between survey variables that best fit the evolution of economic activity. As there is an arbitrary functional relationship between the set of survey variables (Table 1), we link them to the actual percentage growth rate of GDP by means of a SR model:

$y_{i t}=f\left(x 1_{i t}, x 2_{i t}, x 3_{i t}, x 4_{i t}, x 5_{i t}, x 6_{i t}, x 7_{i t}, x 8_{i t}, x 9_{i t}, x 10_{i t}, x 11_{i t}, x 12_{i t}\right)$

where $x 1_{i t}, \ldots, x 12_{i t}$ are the different survey variables, and $y_{i t}$ is a scalar referring to the year-on-year growth rate of quarterly GDP for country $i$ at time $t$. We divide the set of survey variables into three types: judgements about the present economic situation $\left(x 1_{i t}, x 2_{i t}, x 3_{i t}\right)$, perceptions about the present economic situation compared to last year $\left(x 4_{i t}, x 5_{i t}, x 6_{i t}\right)$, and expectations for the next six months about the economic situation $\left(x 7_{i t}, x 8_{i t}, x 9_{i t}\right)$ and the foreign trade volume $\left(x 10_{i t}, x 11_{i t}, x 12_{i t}\right)$. See Table 1. 
Table 1. Explanatory variables (WES expectational indicators)

\begin{tabular}{lll}
\hline Judgements & Overall economy & $x 1_{i t}$ \\
Present & Capital expenditures & $x 2_{i t}$ \\
Economic situation & Private consumption & $x 3_{i t}$ \\
\hline Perceptions & Overall economy & $x 4_{i t}$ \\
Compared to last year & Capital expenditures & $x 5_{i t}$ \\
Economic situation & Private consumption & $x 6_{i t}$ \\
\hline Expectations & Overall economy & $x 7_{i t}$ \\
For the next 6 months & Capital expenditures & $x 8_{i t}$ \\
Economic situation & Private consumption & $x 9_{i t}$ \\
\hline Foreign trade volume & Volume of exports & $x 10_{i t}$ \\
& Volume of imports & $x 11_{i t}$ \\
& Trade balance & $x 12_{i t}$ \\
\hline
\end{tabular}

By means of GP we evolve the symbolic mathematical expressions, until a stopping criterion is reached, be it a predetermined value of the fitness function or a given number of generations. We want to note that there is a trade-off between fitness and complexity. To deal with the growth in the complexity of the SR function we introduced a term that penalized the functions that exceeded a given number of terms. In this study we have chosen a maximum number of 150 generations as as stopping criterion. In Table 2 we summarize the steps for implementing GP.

Table 2. GP implementation - Steps

\begin{tabular}{ll}
\hline $\begin{array}{l}\text { 1. Creation of an initial population of programs } \\
\text { 2. Evaluation of fitness for each program }\end{array}$ & $\begin{array}{l}1,000 \\
\text { Root mean square error (RMSE) }\end{array}$ \\
\hline $\begin{array}{l}\text { 3. Selection of a reproduction strategy } \\
\text { 4. Application of genetic operators }\end{array}$ & Tournament method (size 3) \\
\hline 5. Determination of constants & Mutation probability 0.1 \\
6. Creation of a new population & Automatically generated \\
\hline
\end{tabular}

(1) First, to start the process an initial population of 1000 programs was created.

(2) Then, for each member of the population, an error metric was calculated. We used the Root Mean Square Error (RMSE) as a fitness function.

(3) From the existing strategies for the selection of parents for replacement, which are the programs used to create offspring programs, we used the tournament method so as to guarantee diversity in the population. This method is based on the selection of the fittest individual in each tournament among a group of individuals chosen at random from the 
population. One of the main advantages over other alternative methods is that the selection pressure can be easily adjusted and it is code-efficient.

(4) Then, genetic operators (crossover and mutation) are applied to the parents selected on the basis of the fitness function. Crossover consists on the recombination of randomly chosen parts of parents, while mutation on randomly altering a part of a parent.

(5) We included the automatic generation of constants provided by the GA. This set of constants is optimised after a number of generations to avoid the search path to deviate from the optimum.

(6) As the process evolves, the fitness of the population increases as steps three and four are repeated until the creation of a new population in each generation once a required minimal fitness has been achieved. In this experiment we have chosen a maximum number of 150 generations as a stopping criterion.

The output of this process is a set with the best individual functions from all generations. In this study we have used the open source Distributed Evolutionary Algorithms Package (DEAP) framework implemented in Python (Fortin et al. 2012; Gong et al. 2015).

\section{Results}

In this section we present the results of the experiment. The SR has been estimated using survey data from the CESIfo WES for 28 countries of the OECD, and GDP data retrieved from the OECD web (https://data.oecd.org/gdp/quarterly-gdp.htm\#indicator-chart). The sample period goes from the second quarter of 2000 to the first quarter of 2014. The WES is carried out by the CESIfo Institute for Economic Research. The questionnaire asks respondents whether they expect their country's general economic situation to get better, worse, or to remain unchanged. Qualitative responses are transformed by means of a grading procedure consisting in giving a rank of 9 to positive replies, of 5 to indifferent replies, and of 1 to negative replies (CESifo World Economic Survey, 2011). Survey results are published as aggregated data by country, weighting the results according to the country's share of trade worldwide. See Henzel and Wollmershäuser (2005), Stangl (2007, 2008), and Hutson et al. (2014) for a detailed analysis of WES data. 
Using as a criterion the correlation coefficients between the elements of the population and the dependent value, we have selected a set of building blocks (Table 3 ) for the top 20 functions returned by the GP algorithm.

Table 3. SR-generated indicators (building blocks)

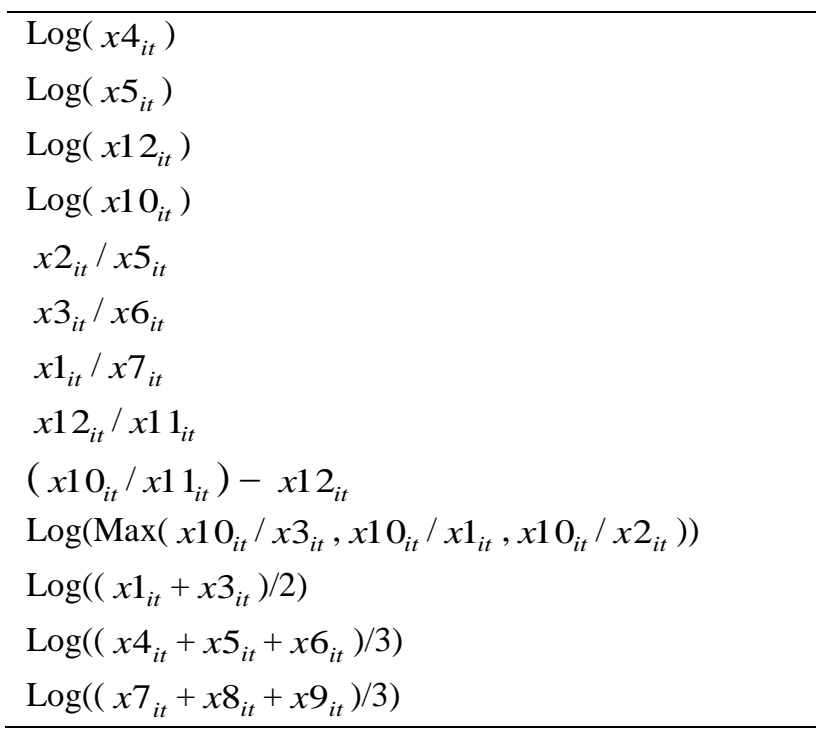

The building blocks in Table 3 are then introduced as regressors of GDP growth so as to obtain the coefficients used to generate the optimal linear combination to track the evolution of economic growth. In order to assess the GP-generated forecasts of GDP, we first compare the evolution of the obtained estimations of economic growth to that of the Economic Climate Index (ECI) constructed by the Ifo. The ECI is an aggregate indicator obtained as the arithmetic mean of assessments of the general economic situation and the expectations for the economic situation in the next six months. The trend in the ECI tends to correlate closely with the actual business-cycle trend measured in annual growth rates of real GDP (Garnitz et al. 2015). In Table 4 we present a descriptive analysis of the ECI for the four Scandinavian economies analysed in this study.

Table 4. Descriptive statistics (Economic Climate Indicator)

\begin{tabular}{lccccc}
\hline & mean & $\begin{array}{c}\text { standard } \\
\text { deviation }\end{array}$ & $\begin{array}{c}\text { variation } \\
\text { coefficient }(\%)\end{array}$ & skewness & kurtosis \\
\hline Denmark & 5.73 & 1.14 & $20.0 \%$ & -0.09 & -1.02 \\
Finland & 5.94 & 1.22 & $20.5 \%$ & -0.49 & -0.59 \\
Norway & 6.71 & 0.99 & $14.7 \%$ & -1.20 & 0.97 \\
Sweden & 5.71 & 1.28 & $22.3 \%$ & -0.58 & -0.07 \\
\hline
\end{tabular}


Fig. 1. Evolution of Ifo Economic Climate indicator vs. proposed survey-based economic indicator

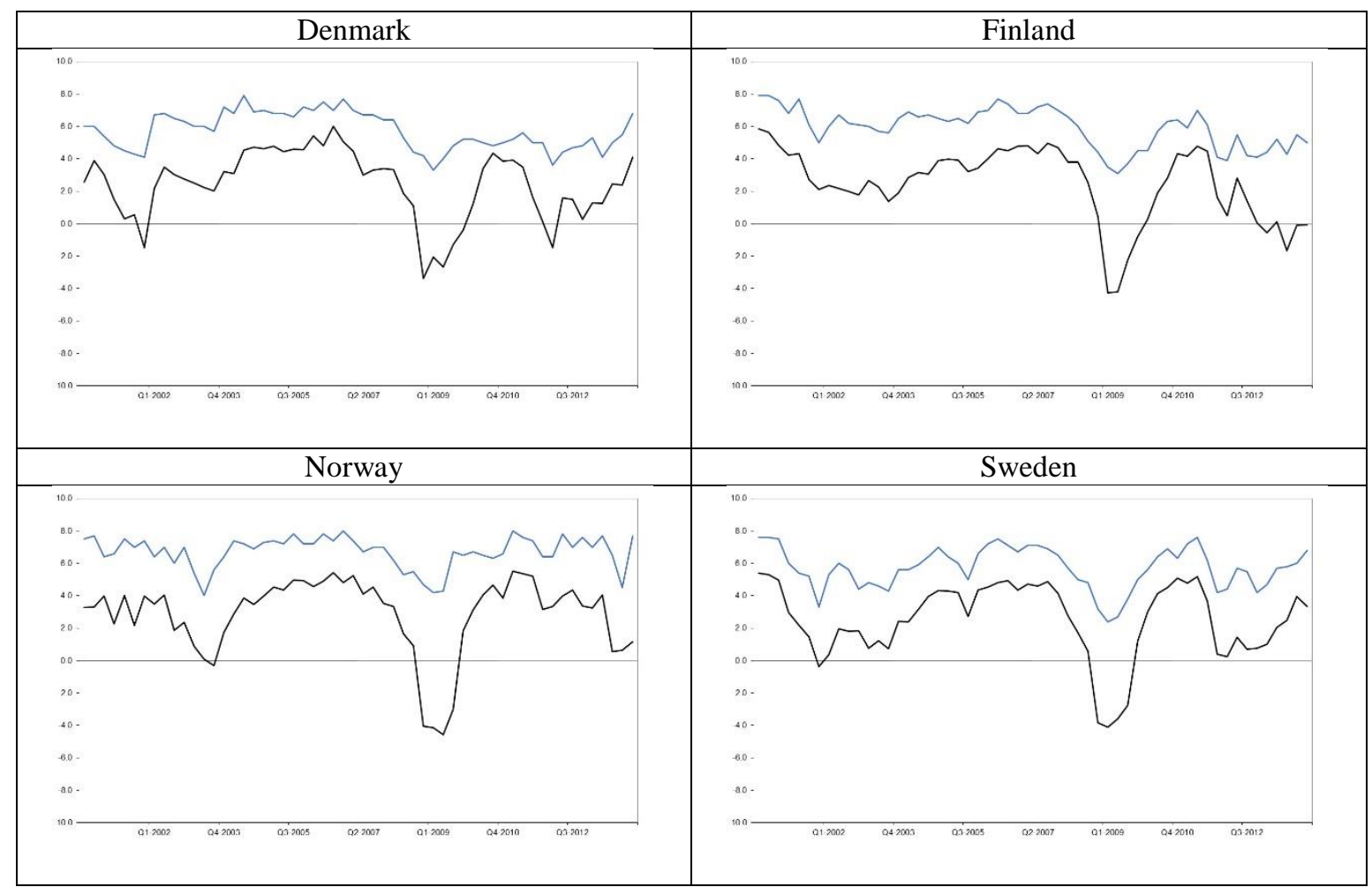

1. Note: Compiled by the author. The grey line represents the evolution of the Ifo Economic Climate indicator in each country. The black line represents the evolution of the proposed survey-based economic indicator.

Fig. 2. Evolution of year-on-year GDP growth rates vs. proposed survey-based economic indicator

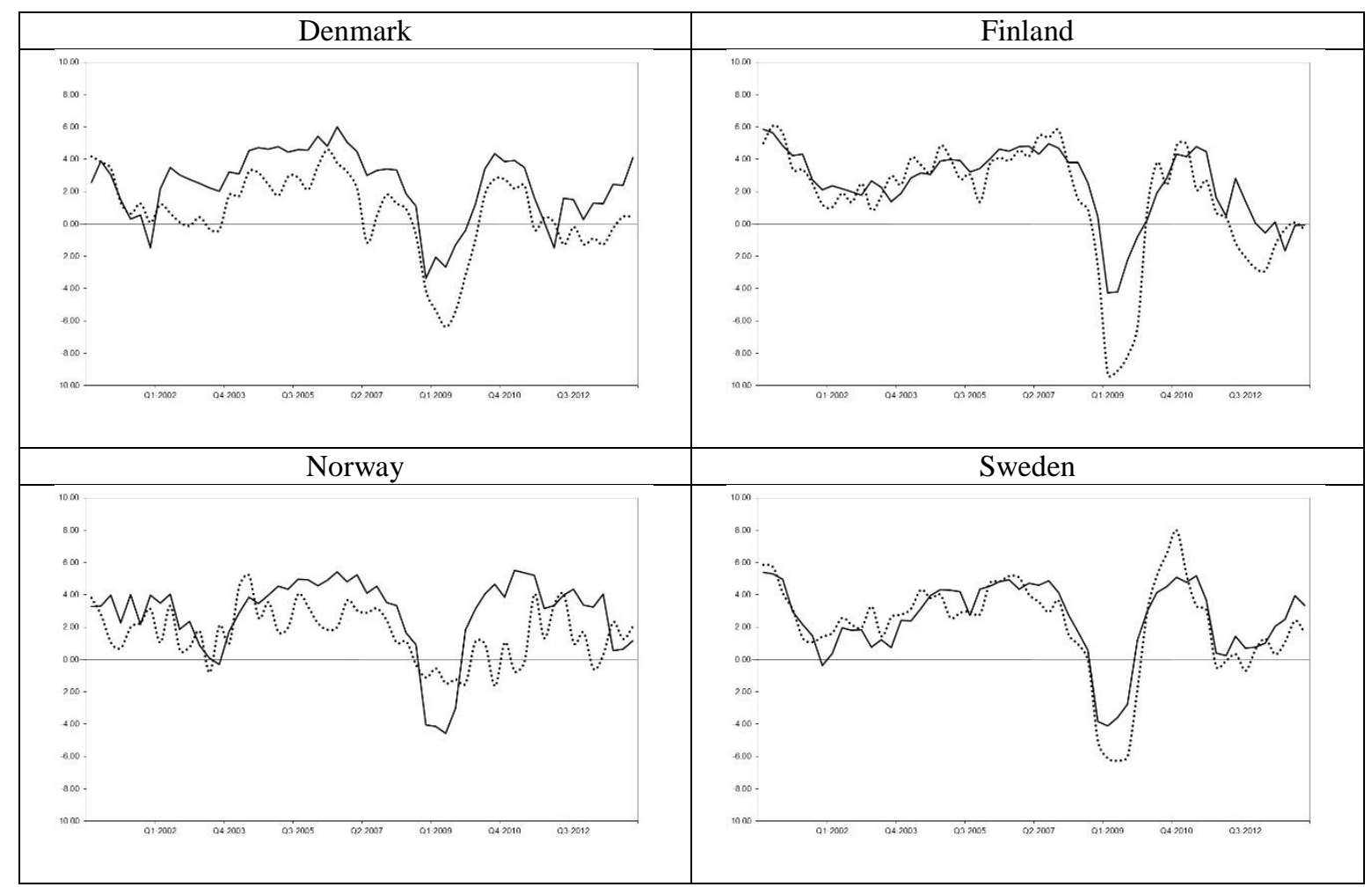

2. Note: Compiled by the author. The dotted line represents the year-on-year growth rate of GDP in each country. The black line represents the evolution of the proposed survey-based economic indicator. 
Fig. 1 compares the evolution of the GP-generated forecasts and the ECI, which show a similar pattern of evolution. The main difference resides in the scale, especially during the 2008 financial crisis, when the ECI downward reaction is of lesser magnitude.

In Fig. 2 we compare the evolution of the GP forecasts to that the year-on-year growth rates of GDP. We can observe that GR-based estimates seem to correlate closely with the actual oscillations of GDP. In all four economies agents' expectations seem to advance turning points, especially regarding the 2008 financial crisis. The severity of the crisis varies across countries, being Sweden, and especially Finland, the economies showing the highest percentages of decrease in the activity. At the opposite end, Norway shows the lowest decline in terms of GDP growth, being the only country in which the GRgenerated forecasts from agents' expectations overestimate the extent of the crisis.

After the graphical analysis, we evaluate the forecasting performance of the quantified expectations by comparing them to a benchmark model in order to compute the MASE. This measure of forecast accuracy was developed by Hyndman and Koehler (2006), who proposed scaling the forecast errors by the in-sample mean absolute error (MAE) obtained with a random walk. As official data are published with a delay of more than a quarter with respect to survey data, we use two-step ahead naïve forecasts as a baseline. The MASE statistic presents several advantages over other forecast accuracy measures. First, it is independent of the scale of the data. Second, it does not suffer from some of the problems presented by other relative measures of forecast accuracy such as the relative MAE. Finally, it is easy to interpret: values larger than one are indicative that the GPbased forecasts are worse than the average prediction computed in-sample with the baseline model.

If we denote the forecast error obtained by means of GP as $e_{t}=Y_{t}-\hat{Y}_{t}$, the scale error is defined as:

$q_{t}=\frac{e_{t}}{\frac{1}{n-1} \sum_{i=3}^{n}\left|Y_{i}-Y_{i-2}\right|}$

Hence, the MASE is obtained as the mean of $q_{t}, \operatorname{MASE}=$ mean $\left(\left|q_{t}\right|\right)$.

With the aim of assessing the potential influence of the 2008 financial crisis on the forecasting accuracy of GP-generated estimates of GDP, we re-compute the MASE differentiating between the pre-crisis subperiod (2000-2007), the crisis (2007-2010), and the post-crisis subperiod (Table 5). 
Table 5. Forecast accuracy by country

\begin{tabular}{llll}
\hline & MASE & & MASE \\
\hline Denmark & 1.250 & Norway & 1.321 \\
Finland & 0.682 & Sweden & 0.586 \\
\hline MASE & Pre-crisis & Crisis & Post-crisis \\
\hline Denmark & 1.074 & 1.509 & 1.298 \\
Finland & 0.368 & 1.091 & 0.831 \\
Norway & 1.024 & 1.622 & 1.570 \\
Sweden & 0.422 & 0.876 & 0.572 \\
\hline
\end{tabular}

The results in Table 5 show that forecast accuracy of the estimates of GDP significantly worsened during the crisis in all countries. Agents' expectations are more accurate in the post-crisis than in the pre-crisis years in all four economies. These results are in line with those of Łyziak and Mackiewicz-Łyziak (2014), who found that the 2008 financial crisis period led to a decrease in expectational errors in transition economies. Similarly, Girardi (2014) found that survey expectations contained relevant information about business cycle developments in the EA, especially around periods of extreme cyclical swings. Vermeulen (2014) found that Carlson-Parkin type indices outperformed the balance indices during periods with higher output volatilities. In a recent study, Lahiri and Zhao (2015) also found a significant improvement in agents' expectations accuracy during periods of uncertainty marked by high levels of disagreement between respondents. By contrast, using survey expectations for Croatia, Erjavec et al. (2015) found that consumers' bias regarding inflation diminished in times of lower price volatility.

\section{Concluding remarks and future work}

Evolutionary computation is increasingly being used for economic applications. In this study we implement GP to find the most fitted mathematical functional forms linking survey expectations to economic growth. By linearly combining the output of this GPgenerated set of models, we estimate the evolution of GDP in Scandinavian economies. The proposed approach demonstrates the potential of survey expectations for economic forecasting and circumvents the issue of quantifying qualitative expectations on the direction of change. Thus, this data-driven method for modelling survey-based agents' 
expectations avoids making assumptions about the subjective probability distribution of respondents.

SR via GP allows selecting the fittest models of interaction between agents' expectations and the official quantitative series they refer to. As a result, the evolution of the GP-generated forecasts correlates closely with the actual oscillations of the economic activity and with other official economic indicators such as the ECI. This result suggests that this empirical approach to model survey expectations on the direction of change may provide gains in forecast accuracy.

We have also analysed the impact of the 2008 financial crisis on the accuracy of agents' expectations by assessing the capacity of GP-generated estimates of GDP to anticipate future economic growth. We have found that the crisis period has led to a deterioration in the forecasting performance of agents' expectations in Scandinavian economies.

Despite the versatility of the proposed GP approach for modelling survey-based expectations to estimate economic growth, some aspects have been left for further research. We have not evaluated to what extent the forecasting performance of GP predictions could have been improved by increasing the maximum number of generations. There is also the question of whether the implementation of improved adaptive algorithms, such as Ferreira's gene expression programming or Zelinka's analytical programming, may improve the forecasting performance of computationally generated economic forecasts. Finally, another issue left for future research is the use of GP-based expectations to assess empirically observed economic relationships such as the Phillips curve, or to test the rational expectations hypothesis.

\section{References}

Abberger, K. (2007). Qualitative business surveys and the assessment of employment - A case study for Germany. International Journal of Forecasting, 23(2), 249-258.

Altug, S., \& Çakmakli, C. (2016). Forecasting inflation using survey expectations and target inflation: Evidence from Brazil and Turkey. International Journal of Forecasting, 32(1), $138-153$.

Acosta-González, E., \& Fernández-Rodríguez, F. (2014). Forecasting financial failure of firms via genetic algorithms. Computational Economics, 43(2), 133-147.

Acosta-González, E., Fernández-Rodríguez, F., \& Sosvilla-Rivero, S. (2012). On factors explaining the 2008 financial crisis. Economics Letters, 115(2), 215-217. 
Acosta-González, E., Fernández-Rodríguez, F., \& Sosvilla-Rivero, S. (2014). An empirical examination of the determinants of the shadow economy. Applied Economics Letters, 21(5), 304-307.

Álvarez-Díaz, M., \& Álvarez, A. (2005). Genetic multi-model composite forecast for nonlinear prediction of exchange rates. Empirical Economics, 30(3), 643-663.

Álvarez-Díaz, M., Mateu-Sbert, J., \& Rosselló-Nadal, J. (2009). Forecasting tourist arrivals to Balearic Islands using genetic programming. International Journal of Computational Economics and Econometrics, 1(1), 64-75.

Anderson, O. (1952). The Business Test of the IFO-Institute for Economic Research, Munich, and its theoretical model. Revue de l'Institut International de Statistique, 20, 1-17.

Barmpalexis, P., Kachrimanis, K., Tsakonas, A., \& Georgarakis, E. (2011). Symbolic regression via genetic programming in the optimization of a controlled release pharmaceutical formulation. Chemometrics and Intelligent Laboratory Systems, 107(1), 75-82.

Batchelor, R., \& Dua, P. (1992). Survey expectations in the time series consumption function. The Review of Economics and Statistics, 74(4), 598-606.

Batchelor, R., \& Dua, P. (1998). Improving macro-economic forecasts. International Journal of Forecasting, 14(1), 71-81.

Bergström, R. (1995). The relationship between manufacturing production and different business survey series in Sweden 1968-1992. International Journal of Forecasting, 11(3), 379-393.

Berk, J. M. (1999). Measuring inflation expectations: A survey data approach. Applied Economics, 31(11), 1467-1480.

Białowolski, P. (2016). The influence of negative response style on survey-based household inflation expectations. Quality \& Quantity, 50(2), 509-528.

Bovi, M. (2013). Are the representative agent's beliefs based on efficient econometric models? Journal of Economic Dynamics \& Control, 37(3), 633-648.

Breitung, J., \& Schmeling, M. (2013). Quantifying survey expectations: What's wrong with the probability approach? International Journal of Forecasting, 29(1), 142-154.

Bruestle, P., \& Crain, W. M. (2015). A mean-variance approach to forecasting with the consumer confidence index. Applied Economics, 47(23), 2430-2444.

Bruno, P. (2014). Consumer confidence and consumption forecast: A non-parametric approach. Empirica, 41(1), 37-52.

Cai, W., Pacheco-Vega, A., Sen, M., \& Yang, K. T. (2006). Heat transfer correlations by symbolic regression. International Journal of Heat and Mass Transfer, 49(23-24), 43524359.

Can, B., and C. Heavey. 2011. "Comparison of Experimental Designs for Simulation-based Symbolic Regression of Manufacturing Systems." Computers \& Industrial Engineering 61, no. 3: 447-462.

Ceperic, V., Bako, N., \& Baric, A. (2014). A symbolic regression-based modelling strategy of AC/DC rectifiers for RFID applications. Expert Systems with Applications, 41(16), 70617067.

CESifo World Economic Survey (2011). Vol. 10(2), May 2011.

Chen, X., Pang, Y., \& Zheng, G. (2010). Macroeconomic forecasting using GP based vector error correction model. In J. Wang (Ed.), Business Intelligence in Economic Forecasting: Technologies and Techniques (pp. 1-15). Hershey, PA: IGI Global.

Chen, S. H., \& Kuo, T. W. (2002). Evolutionary computation in economics and finance: A bibliography. In S. H. Chen (Ed.), Evolutionary Computation in Economics and Finance (pp. 419-455). Heidelberg: Physica-Verlag.

Chen, S. H., Kuo, T. W., \& Hoi, K. M. (2008). Genetic programming and financial trading: How much about "what we know". In C. Zopounidis et al. (Eds.), Handbook of financial engineering (pp. 99-154). New York: Springer.

Claveria, O. (2010). Qualitative survey data on expectations. Is there an alternative to the balance statistic? In A. T. Molnar (Ed.), Economic Forecasting (pp. 181-190). Hauppauge, NY: Nova Science Publishers. 
Claveria, O., Pons, E., \& Ramos, R. (2007). Business and consumer expectations and macroeconomic forecasts. International Journal of Forecasting, 23(1), 47-69.

Common, M. (1985). Testing for rational expectations with qualitative survey data. Manchester School of Economic and Social Statistics, 53(2), 138-148.

Cramer, N. (1985). A representation for the adaptive generation of simple sequential programs. Proceedings of the International Conference on Genetic Algorithms and their Applications, 24-26 June. Pittsburgh, PA.

Dabhi, V. K., \& Chaudhary, S. (2015). Empirical modeling using genetic programming: A survey of issues and approaches. Natural Computing, 14(2), 303-330.

Dees, S., \& Brinca, P. S. (2013). Consumer confidence as a predictor of consumption spending: Evidence for the United States and the Euro area. International Economics, 134, 1-14.

Drake, A. E., \& Marks, R. E. (2008). Genetic algorithms in economics and finance: Forecasting stock market prices and foreign exchange $-\mathrm{A}$ review. In S. H. Chen (Ed.), Genetic Algorithms and Genetic Programming in Computational Finance (pp. 29-54). New York: Springer.

Driver, C., \& Urga, G. (2004). Transforming qualitative survey data: Performance comparisons for the UK. Oxford Bulletin of Economics and Statistics, 66(1), 71-89.

Duda, J., \& Szydło, S. (2011). Collective intelligence of genetic programming for macroeconomic forecasting. In P. Jędrzejowicz et al. (Eds.), Computational Collective Intelligence. Technologies and Applications (pp. 445-454). Berlin: Springer.

Erjavec, N., Lolić, I., \& Sorić, P. (2015). How (i)rrational are we? A case of Croatian inflation. Croatian Operational Research Review, 6, 241-253.

Ferreira, C. (2001). Gene expression programming: A new adaptive algorithm for solving problems. Complex Systems, 13(2), 87-129.

Fogel, D. B. (2006). Evolutionary computation. Toward a new philosophy of machine intelligence (Third Edition). Hoboken, NJ: John Wiley \& Sons.

Fogel, L. J., Owens, A. J., \& Walsh, M. J. (1966). Artificial intelligence through simulated evolution. New York: John Wiley.

Fortin, F. A., De Rainville, F. M., Gardner, M. A., Parizeau, M., \& Gagné, C. (2012). DEAP: Evolutionary algorithms made easy. Journal of Machine Learning Research, 13(1), 21712175.

Gandomi, A. H., \& Roke, D. A. (2015). Assessment of artificial neural network and genetic programming as predictive tools. Advances in Engineering Software, 88(C), 63-72.

Garnitz, J., Nerb, G., \& Wohlrabe, K. (2015). CESifo World Economic Survey - November 2015. CESifo World Economic Survey, 14(4), 1-28.

Ghonghadze, J., \& Lux, T. (2012). Modelling the dynamics of EU economic sentiment indicators: An interaction-based approach. Applied Economics, 44(24), 3065-3088.

Girardi, A. (2014). Expectations and macroeconomic fluctuations in the euro area. Economics Letters, 125(2), 315-318.

Goldberg, D. E. (1989). Genetic algorithms in search, optimization, and machine learning. Reading Boston, MA: Addison-Wesley.

Gong, Y. J., Chen, W. N., Zhan, Z. H., Zhang, J., Li, Y., Zhang, Q., \& Li, J. J. (2015). Distributed evolutionary algorithms and their models: A survey of the stat-of-the-art. Applied Soft Computing, 34, 286-300.

Graff, M. (2010). Does a multi-sectoral design improve indicator-based forecasts of the GDP growth rate? Evidence from Switzerland. Applied Economics, 42(21), 2759-2781.

Guizzardi, A., \& Stacchini, A. (2015). Real-time forecasting regional tourism with business sentiment surveys. Tourism Management, 47, 213-223.

Hansson, J., Jansson, P., \& Löf, M. (2005). Business survey data: Do they help in forecasting GDP growth?. International Journal of Forecasting, 30(1), 65-77.

Henzel, S., \& Wollmershäuser, T. (2005). An alternative to the Carlson-Parkin method for the quantification of qualitative inflation expectations: Evidence from the Ifo World Economic Survey. Journal of Business Cycle Measurement and Analysis, 2(3), 321-352.

Holland, J. H. (1975). Adaptation in natural and artificial systems. Ann Arbor, MI: University of Michigan Press. 
Huang, C. F., Hsu, C. J., Chen, C. C., Chang, B. R., \& Li, C.-A. (2015). An intelligent model for pairs trading using genetic algorithms. Computational Intelligence and Neuroscience, $2015,1-10$.

Huang, G.-B., Zhu, Q.-Y., \& Siew, C.-K. (2006). Extreme learning machine: Theory and applications. Neurocomputing, 70(1-3), 489-501.

Hutson, M., Joutz, F., \& Stekler, H. (2014). Interpreting and evaluating CESIfo's World Economic Survey directional forecasts. Economic Modelling, 38, 6-11.

Hyndman, R. J., \& Koehler, A. B. (2006). Another look at measures of forecast accuracy. International Journal of Forecasting, 22(4), 679-688.

Jean-Baptiste, F. (2012). Forecasting with the new Keynesian Phillips curve: Evidence from survey data. Economics Letters , 117(3) 811-813.

Jonsson, T., \& Österholm, P. (2012). The properties of survey-based inflation expectations in Sweden. Empirical Economics, 42(1), 79-94.

Kaboudan, M. A. (2000). Genetic programing prediction of stock prices. Computational Economics, 16(3), 207-236.

Kapetanios, G., Marcellino, M., \& Papailias, F. (2016). Forecasting inflation and GDP growth using heuristic optimisation of information criteria and variable reduction methods. Computational Statistics and Data Analysis, 100, 369-382.

Kauppi, E., Lassila, J., \& Teräsvirta, T. (1996). Short-term forecasting of industrial production with business survey data: Experience from Finland's great depression 1990-1993. International Journal of Forecasting, 12(3), 373-381.

Klein L. R., \& Özmucur, S. (2010). The use of consumer and business surveys in forecasting. Economic Modelling, 27(6), 1453-1462.

Kl'účik, M. (2012). Estimates of foreign trade using genetic programming. Proceedings of the 46 the scientific meeting of the Italian Statistical Society.

Kotanchek, M. E, Vladislavleva, E. Y., \& Smits, G. F. (2010). Symbolic regression via genetic programming as a discovery engine: Insights on outliers and prototypes. In R. Riolo et al., (Eds.), Genetic Programming Theory and Practice VII, Genetic and Evolutionary Computation Vol. 8 (pp. 55-72). Springer Science+Business Media, LLC.

Koza, J. R. (1992). Genetic programming: On the programming of computers by means of natural selection. Cambridge, MA: MIT Press.

Koza, J. R. (1995). Genetic Programming for econometric modeling. In S. Goonatilaje and P. Treleaven (Eds.), Intelligent Systems for Finance and Business (pp. 251-269). London: John Wiley and Sons.

Krömer, P., Owais, S., Platoš, J., \& Snášel, V. (2013). Towards new directions of data mining by evolutionary fuzzy rules and symbolic regression. Computers and Mathematics with Applications, 66(2), 190-200.

Kronberger, G., Fink, S., Kommenda, M., \& Affenzeller, M. (2011). Macro-economic time series modeling and interaction networks. In C. Di Chio et al. (Eds.), EvoApplications, Part II (pp. 101-110). LNCS 6625.

Lahiri, K., \& Zhao, Y. (2015). Quantifying survey expectations: A critical review and generalization of the Carlson-Parkin method. International Journal of Forecasting, 31(1), $51-62$.

Larkin, F., \& Ryan, C. (2008). Good news: Using news feeds with genetic programming to predict stock prices. In M. O’Neil et al. (Eds.), Genetic Programming (pp. 49-60). Berlin: Springer-Verlag.

Leduc, S., \& Sill, K. (2013). Expectations and economic fluctuations: An analysis using survey data. The Review of Economic and Statistics, 95(4), 1352-1367.

Lee, K. C. (1994). Formation of price and cost inflation expectations in British manufacturing industries: A multi-sectoral analysis. Economic Journal, 104(423), 372-385.

Lehmann, R., \& Wohlrabe, K. (2017). Experts, firms, consumers or even hard data? Forecasting employment in Germany. Applied Economics Letters, 24(4), 279-283.

Löffler, G. (1999). Refining the Carlson-Parkin method. Economics Letters, 64(2), 167-71. 
Lui, S., Mitchell, J., \& Weale, M. (2011a). The utility of expectational data: firm-level evidence using matched qualitative-quantitative UK surveys. International Journal of Forecasting, 27(4), 1128-1146.

Lui, S., Mitchell, J., \& Weale, M. (2011b). Qualitative business surveys: signal or noise?. Journal of The Royal Statistical Society, Series A (Statistics in Society), 174(2), 327-348.

Łyziak, T., \& Mackiewicz-Łyziak, J. (2014). Do consumers in Europe anticipate future inflation? Eastern European Economics, 52(3), 5-32.

Marković, D., Petković, D., Nikolić, V., Milovančević, M., \& Petković, B. (2017). Soft computing prediction of economic growth based in science and technology factors. Physica A, 465, 217-220.

Martinsen, K., Ravazzolo, F., \& Wulfsberg, F. (2014). Forecasting macroeconomic variables using disaggregate survey data. International Journal of Forecasting, 30(1), 65-77.

Maschek, M. K. (2010). Intelligent mutation rate control in an economic application of genetic algorithms. Computational Economics, 35(1), 25-49.

Milutinović, B., Stefanović, G., Đekić, P. S., Mijailović, I., \& Tomić, M. (2017). Environmental assessment of waste management scenarios with energy recovery using life cycle assessment and multi-criteria analysis. Energy. Forthcoming.

Milutinović, B., Stefanović, G., Jović, S., \& Škrijelj, H. (2015). Development of mathematical model for estimation of economic indicators of waste treatment. Proceedings of the 5th International Symposium on Mining and Environmental Protection (Vrdnik), pp. 162170.

Mitchell, J. (2002). The use of non-normal distributions in quantifying qualitative survey data on expectations. Economics Letters, 76(1), 101-107.

Mitchell, J., Smith, R., \& Weale, M. (2002). Quantification of qualitative firm-level survey data. Economic Journal, 112(478), 117-135.

Mitchell, J., Smith, R., \& Weale, M. (2005a). Forecasting manufacturing output growth using firm-level survey data. The Manchester School, 73(4), 479-499.

Mitchell, J., Smith, R., \& Weale, M. (2005b). An indicator of monthly GDP and an early estimate of quarterly GDP growth. The Economic Journal, 115(501), F108-F129.

Mittnik, S., \& Zadrozny, P. (2005). Forecasting quarterly German GDP at monthly intervals using monthly IFO business conditions data (2005). In J. E. Sturm and T. Wollmershäuser (Eds.), IFO survey data in business cycle analysis and monetary policy analysis (pp. 1948). Heidelberg: Physica-Verlag.

Mokinski, F., Sheng, X., \& Yang, J. (2015). Measuring disagreement in qualitative expectations. Journal of Forecasting, 34(5), 405-426.

Müller, C. (2010). You CAN Carlson-Parkin. Economics Letters, 108(1), 33-35.

Nardo, M. (2003). The quantification of qualitative data: a critical assessment. Journal of Economic Surveys, 17(5), 645-668.

Nolte, I., \& Pohlmeier, W. (2007). Using forecasts of forecasters to forecast. International Journal of Forecasting, 23(1), 15-28.

Österholm, P. (2014). Survey data and short-term forecasts of Swedish GDP growth. Applied Economics Letters, 21(2), 135-139.

Peng, Y., Yuan, C., Qin, X., Huang, J., \& Shi, Y. (2014). An improved gene expression programming approach for symbolic regression problems. Neurocomputing, 137, $293-$ 301.

Pesaran, M. H. (1984). Expectation formation and macroeconomic modelling. In P. Malgrange and P. A. Muet (Eds.), Contemporary Macroeconomic Modelling (pp. 27-55). Basil Blackwell: Oxford.

Pesaran, M. H. (1985). Formation of inflation expectations in British manufacturing industries. Economic Journal, 95(380), 948-975.

Pesaran, M. H., \& Weale, M. (2006). Survey Expectations. In G. Elliott, C. W. J. Granger, and A. Timmermann (Eds.), Handbook of Economic Forecasting, Vol. 1 (pp. 715-776). Amsterdam: Elsevier North- Holland. 
Petković, D. (2015). Adaptive neuro-fuzzy optimization of the net present value and internal rate of return of a wind farm project under wake effect. JCC: The Business and Economics Research Journal, 8(1), 11-28.

Poli, R., Vanneschi, L., Langdon, W. B., \& Mcphee, N. F. (2010). Theoretical Results in Genetic Programming: The Next Ten Years? Genetic Programming and Evolvable Machines, 11(3), 285-320.

Qiao, Z., McAleer, M., \& Wong, W. K. (2009). Linear and nonlinear causality between changes in consumption and consumer attitudes. Economic Letters, 102(3), 161-164.

Rahiala, M., \& Teräsvirta, T. (1993). Business survey data in forecasting the output of Swedish and Finnish metal and engineering industries: A Kalman filter approach. Journal of Forecasting, 12(3-4), 255-271.

Ramos-Herrera, M. C., \& Acosta-González, E. (2017). Factors determining exchange rate stability in member and candidate States of the European Union: An analysis based on genetic algorithms. Cuadernos de Economía, 40(112), 68-82.

Robinzonov, N., Tutz, G., \& Hothorn, T. (2012). Boosting techniques for nonlinear time series models. AStA Advances in Statistical Analysis, 96(1), 99-122.

Sarradj, E., \& Geyer, T. (2014). Symbolic regression modeling of noise generation at porous airfoils. Journal of Sound and Vibration, 333(14), 3189-3202.

Schmeling, M., \& Schrimpf, A. (2011). Expected inflation, expected stock returns, and money illusion: What can we learn from survey expectations. European Economic Review, 55(5), 702-719.

Sheta, A. F., Ahmed, S. E. M., \& Faris, H. (2015). Evolving stock market prediction models using multi-gene symbolic regression genetic programming. Artificial Intelligence and Machine Learning, 15(1), 11-20.

Smith, J., \& McAleer, M. (1995). Alternative procedures for converting qualitative response data to quantitative expectations: an application to Australian manufacturing. Journal of Applied Econometrics, 10(2), 165-185.

Sorić, P., Lolić, I., \& Mačkić, V. (2013). An empirical assessment of the expected inflation quantification methods. A pan-European study. Global Review of Business and Economics Research, 9(2), 117-132.

Stangl, A. (2007). Ifo World Economic Survey micro data. Journal of Applied Social Science Studies, 127(3), 487-496.

Stangl, A. (2008). Essays on the measurement of economic expectations. Dissertation. Munich: Universität München.

Terai, A. (2009). Measurement error in estimating inflation expectations from survey data: an evaluation by Monte Carlo simulations. Journal of Business Cycle Measurement and Analysis, 8(2), 133-156.

Theil, H. (1952). On the time shape of economic microvariables and the Munich Business Test. Revue de l'Institut International de Statistique, 20, 105-20.

Thinyane, H., \& Millin, J. (2011). An investigation into the use of intelligent systems for currency trading. Computational Economics, 37(4), 363-374.

Vasilakis, G. A., Theofilatos, K. A., Georgopoulos, E. F., Karathanasopoulos, A., \& Likothanassis, S. D. (2013). A genetic programming approach for EUR/USD exchange rate forecasting and trading. Computational Economics, 42(4), 415-431.

Vladislavleva, E.; Smits, G., den Hertog, D. (2010). On the importance of data balancing for symbolic regression. IEEE Transactions in Evolutionary Computation, 14(2), 252-277.

Vermeulen, P. (2014). An evaluation of business survey indices for short-term forecasting: Balance method versus Carlson-Parkin method. International Journal of Forecasting, 30(4), 882-897.

Waltman, L., Van Eck, N. J., Dekker, R., \& Kaymak, U. (2011). Economic modeling using evolutionary algorithms: The effect of a binary encoding of strategies. Journal of Evolutionary Economics, 21(5), 737-756.

Wei, L. Y. (2013). A hybrid model based on ANFIS and adaptive expectation genetic algorithm to forecast TAIEX. Economic Modelling, 33, 893-899. 
Wu, C. H., Chou, H. J., \& Su, W. H. (2008). Direct transformation of coordinates for GPS positioning using the techniques of genetic programming and symbolic regression. Engineering Applications of Artificial Intelligence, 21(8), 1347-1359.

Yang, G., Li, X., Wang, J., Lian, L., \& Ma, T. (2015). Modeling oil production based on symbolic regression. Energy Policy, 82(1), 48-61.

Yao, L., \& Lin, C. C. (2009). Identification of nonlinear systems by the genetic programmingbased volterra filter. IET Signal Processing, 3(2), 93-105.

Wilms, I., Gelper, S., \& Croux, C. (2016). The predictive power of the business and bank sentiment of firms: A high-dimensional Granger Causality approach. European Journal of Operational Research, 254(1), 138-147.

Wilson, G., \& Banzhaf, W. (2009). Prediction of interday stock prices using developmental and linear genetic programming. In M. Giacobini et al. (Eds.), Applications of Evolutionary Computing (pp. 172-181). Berlin: Springer-Verlag.

Yu, T., Chen, S., \& Kuo, T. W. (2004). A genetic programming approach to model international short-term capital flow. Applications of Artificial Intelligence in Finance and Economics, $19,45-70$.

Zelinka, I. (2015). A survey on evolutionary algorithms dynamics and its complexity - Mutual relations, past, present and future. Swarm and Evolutionary Computation, 25, 2-14.

Zimmermann, K. F. (1997). Analysis of business surveys. In M. H. Pesaran and P. Schmidt (Eds.), Handbook of Applied Econometrics. Volume II: Microeconomics (pp. 407-441), Blackwell Publishers, Oxford. 